\title{
Methyl jasmonate abolishes the migration, invasion and angiogenesis of gastric cancer cells through down-regulation of matrix metalloproteinase 14
}

Liduan Zheng ${ }^{1,2+}$, Dan $\mathrm{Li}^{3+}$, Xuan Xiang ${ }^{3}$, Ling Tong ${ }^{1}$, Meng Qi ${ }^{3}$, Jiarui Pu ${ }^{3}$, Kai Huang ${ }^{2,4}$ and Qiangsong Tong ${ }^{2,3^{*}}$

\begin{abstract}
Background: Recent evidence indicates that methyl jasmonate (MJ), a plant stress hormone, exhibits anti-cancer activity on human cancer cells. The aim of this study is to determine whether sub-cytotoxic MJ can abolish the migration, invasion and angiogenesis gastric cancer cells.

Methods: Human gastric cancer cell lines SGC-7901 and MKN-45 were treated with diverse concentrations of MJ. Cell viability, proliferation, migration, invasion and angiogenesis capabilities of cancer cells were measured by MTT colorimetry, EdU incorporation, scratch assay, matrigel invasion assay, and tube formation assay. Gene expression was detected by western blot and real-time quantitative RT-PCR. Binding of transcription factor on gene promoter was detected by chromatin immunoprecipitation.

Results: Sub-cytotoxic ( 0.05 to $0.2 \mathrm{mM}$ ) MJ attenuated the migration, invasion and angiogenesis, but not the cell viability or proliferation, of gastric cancer cells in a time- and dose-dependent manner, with down-regulation of matrix metalloproteinase 14 (MMP-14) and its downstream gene vascular endothelial growth factor. Restoration of MMP-14 expression rescued the SGC-7901 and MKN-45 cells from sub-cytotoxic MJ-inhibited migration, invasion and angiogenesis. In addition, sub-cytotoxic MJ decreased the specificity protein 1 (Sp1) expression and binding on MMP-14 promoter, while restoration of Sp1 expression rescued the cancer cells from sub-cytotoxic MJ-mediated defects in MMP-14 expression, migration, invasion and angiogenesis.
\end{abstract}

Conclusions: Sub-cytotoxic MJ attenuates the MMP-14 expression via decreasing the Sp1 expression and binding on MMP-14 promoter, thus inhibiting the migration, invasion and angiogenesis of gastric cancer cells.

Keywords: Gastric cancer, Methyl jasmonate, Matrix metalloproteinase 14, Specificity protein 1

\section{Background}

Gastric cancer is one of the most common cancers worldwide [1]. In spite of the improvement of surgical and multimodal therapy, invasion and metastasis of cancer cells remains the main cause of gastric cancer-

\footnotetext{
* Correspondence: qs_tong@hotmail.com

${ }^{\dagger}$ Equal contributors

${ }^{2}$ Clinical Center of Human Genomic Research, Union Hospital of Tongji Medical College, Huazhong University of Science and Technology, Wuhan, Hubei Province 430022, People's Republic of China

${ }^{3}$ Department of Surgery, Union Hospital of Tongji Medical College, Huazhong University of Science and Technology, Wuhan, Hubei Province 430022, People's Republic of China

Full list of author information is available at the end of the article
}

related death, with a 5-year survival rate below 30\% [2]. Chemotherapy is an appropriate option with the hope of prolonged survival for gastric cancer patients [3]. Currently, over sixty percent of the anti-cancer agents in use are derived from natural sources, including plants, marine organisms and micro-organisms [4]. Plant-derived compounds, such as vinblastine, vincristine, topotecan, irinotecan, etoposide and paclitaxel, have been an important source of clinically useful anti-cancer agents [5], which possess therapeutic effects against cancer cells by modulating cell cycle, proliferation, and viability [5]. Thus, novel anti-cancer plant-derived substances and

\section{() Biomed Central}


treatment regimens are of interest and warrant to be developed.

Plant stress hormones are natural bioregulators in plant intracellular signaling and defense in response to injury or environmental stresses, such as ultraviolet radiation, osmotic shock and heat [6]. Among the plant hormones, salicylic acid and its derivative aspirin are extensively studied as potential anti-cancer therapeutics and chemopreventive agents [6,7]. The jasmonate family, a group of plant stress hormones consisting of cis-jasmone, jasmonic acid, and methyl jasmonate (MJ), are fatty acid-derived cyclopentanones that occur ubiquitously in the plant kingdom and regulate plant developmental processes and adaptation to environment [8]. In recent years, emerging evidence has shown the anticancer effects of naturally occurring jasmonates and their synthetic derivatives $[9,10]$. In general, MJ has been found to be superior to cis-jasmone and jasmonic acid in terms of cytotoxicity and induction of apoptosis in human cancer cells [11,12], suggesting that MJ is a promising agent for the development of cancer therapeutics.

Our previous studies have demonstrated that MJ exerts anti-tumor properties through down-regulating the expression of proliferating cell nuclear antigen, $\mathrm{X}$-linked inhibitor of apoptosis protein, and survivin $[12,13]$. We have also shown that cell permeable sevenresidue peptide of Smac significantly enhances the growth inhibition effects of MJ on prostate cancer cells [14]. However, the potential anti-cancer effects of MJ on gastric cancer and the underlying mechanisms still remain largely unknown. In addition, most of the current studies focus on the cytotoxicity of MJ on cancer cells, while the effects of sub-cytotoxic MJ on the invasion, metastasis and angiogenesis of cancer cells warrant further investigation. In this study, we demonstrate, for the first time, that sub-cytotoxic MJ suppresses the migration, invasion and angiogenesis of gastric cancer cells through attenuating the expression of matrix metalloproteinase 14 (MMP-14) via decreasing the specificity protein 1 ( $\mathrm{Sp} 1$ ) expression and its binding on MMP-14 promoter.

\section{Methods}

\section{Cell culture}

Human gastric cancer cell lines SGC-7901 (moderately differentiated) and MKN-45 (poorly differentiated) were obtained from the Type Culture Collection of Chinese Academy of Sciences (Shanghai, China). Human endothelial cell line HUVEC (CRL-1730) was purchased from American Type Culture Collection (Rockville, MD). The cells were grown in RPMI1640 medium (Life Technologies, Inc., Gaithersburg, MD) supplemented with $10 \%$ fetal bovine serum (Life Technologies, Inc.), penicillin (100 U/ml) and streptomycin $(100 \mu \mathrm{g} / \mathrm{ml})$. Cells were maintained at $37^{\circ} \mathrm{C}$ in a humidified atmosphere of $5 \% \mathrm{CO}_{2}$. MJ (Sigma, St Louis, MO) was prepared into stock solutions at a concentration of $1 \mathrm{~mol} / \mathrm{L}$ in anhydrous dimethyl sulfoxide (Sigma), and stored at $-20^{\circ} \mathrm{C}$. Confluent monolayers of cells were incubated with different concentrations of $\mathrm{MJ}$ for 6, 12 and 24 hrs as indicated. The 50\% inhibitory concentration $\left(\mathrm{IC}_{50}\right)$ of $24 \mathrm{hr}$ exposure, defined as the drug concentration resulting in $50 \%$ reduction of cell viability compared to solvent control, was determined by Bliss's software (Bliss Co, CA).

\section{Patient tissue samples}

Approval to conduct this study was obtained from the Institutional Review Board of Tongji Medical College (approval number: 2010-S003). Specimens of surgically resected primary gastric carcinoma were collected from twenty patients at the Department of Surgery, Union Hospital of Tongji Medical College, Huazhong University of Science and Technology in Wuhan, China. Their pathological diagnosis was proven by at least two pathologists. Adjacent gastric mucosa that contained no macroscopic tumor was also obtained, and the non-neoplastic areas were subsequently verified by microscopic histology to be free of tumor infiltration. Fresh gastric cancer and nonneoplastic tissues were collected and stored at $-80^{\circ} \mathrm{C}$ until use.

\section{Measurement of cell viability}

Cancer cells were cultured in 96-well plates at $5 \times 10^{3}$ cells per well and treated with $\mathrm{MJ}$ or solvent. Cell viability was monitored by the 2-(4,5-dimethyltriazol-2-yl)-2,5-diphenyl tetrazolium bromide (MTT, Sigma) colorimetric assay [15]. All experiments were done with 6-8 wells per experiment and repeated at least three times.

\section{Cell proliferation assay}

Cancer cells were cultured in 96-well plates at $5 \times 10^{3}$ cells per well, treated with $\mathrm{MJ}$ or solvent, and exposed to $50 \mu \mathrm{mol} / \mathrm{L}$ of 5-ethynyl-20-deoxyuridine (EdU, Ribobio, China) for additional $4 \mathrm{hrs}$ at $37^{\circ} \mathrm{C}$. The cells were fixed with $4 \%$ formaldehyde for $15 \mathrm{~min}$ and treated with $0.5 \%$ Triton X-100 for $20 \mathrm{~min}$ at room temperature. After washing with phosphate buffered saline (PBS) for three times, the cells of each well were reacted with $100 \mu \mathrm{l}$ of $1 \times$ Apollo ${ }^{\circledR}$ reaction cocktail for $30 \mathrm{~min}$. Subsequently, the DNA contents of cells in each well were stained with $100 \mu \mathrm{l}$ of Hoechst $33342(5 \mu \mathrm{g} / \mathrm{ml})$ for $30 \mathrm{~min}$ and visualized under a fluorescent microscope.

\section{Scratch migration assay}

Cancer cells were cultured in 24-well plates, treated with MJ or solvent, and scraped with the fine end of 1-ml pipette tips (time 0). Plates were washed twice with PBS 


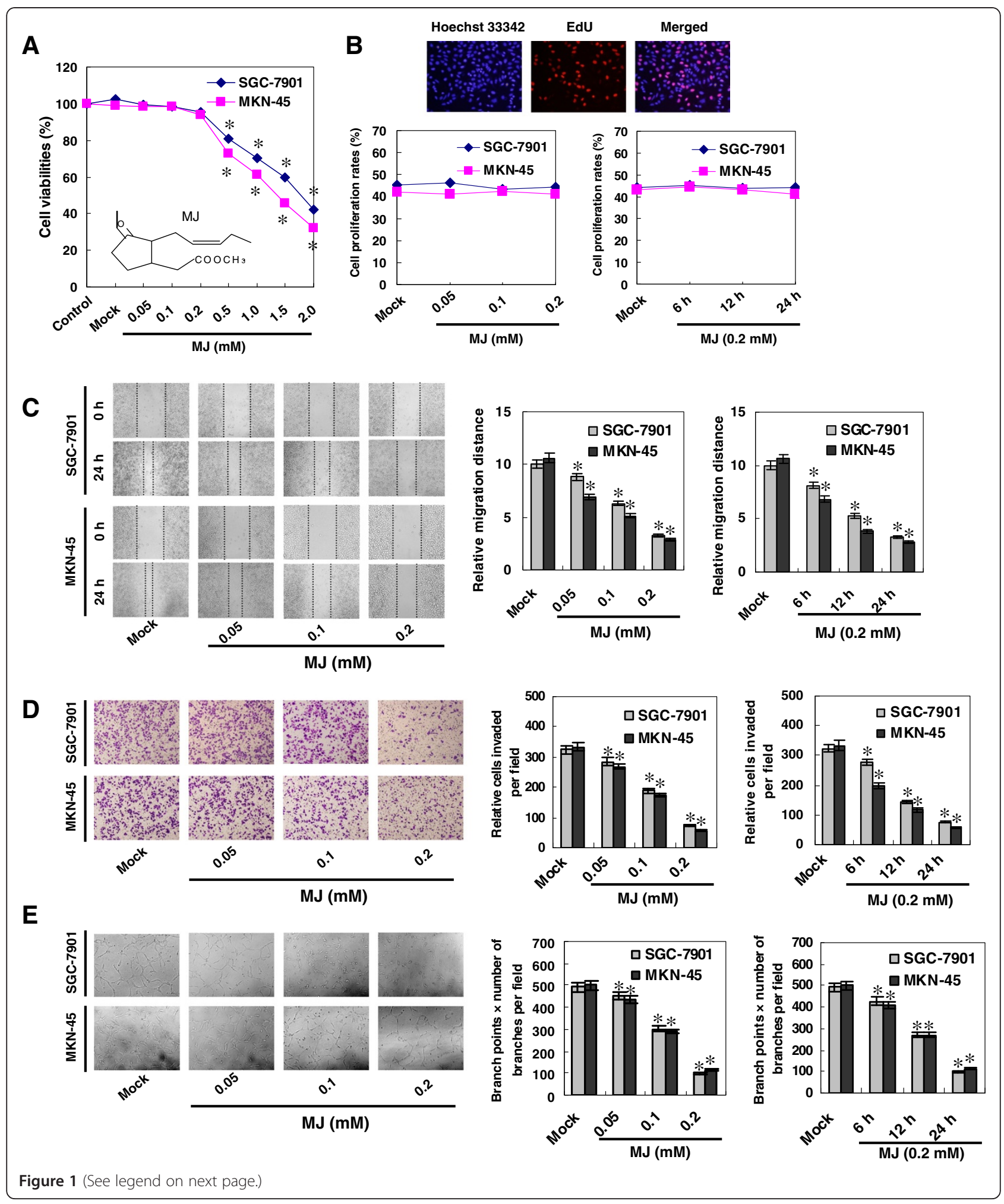


(See figure on previous page.)

Figure 1 Sub-cytotoxic MJ attenuated the migration, invasion and angiogenesis, but not the viabilities or proliferation, of gastric cancer cells. Human gastric cancer cell lines SGC-7901 and MKN-45 were incubated with different concentrations of MJ as indicated. A, MTT colorimetric assay indicated that MJ suppressed the cell viabilities of gastric cancer cells with a range of concentrations ( 0.5 to $2.0 \mathrm{mM})$, while lower concentrations of MJ ( 0.05 to $0.2 \mathrm{mM}$ ) exerted no obvious cytotoxicity, when compared to those of solvent-treated (mock) cells. B, EdU incorporation assay revealed that sub-cytotoxic MJ $(0.05,0.1$ and $0.2 \mathrm{mM})$ did not attenuate the proliferation of SGC-7901 and MKN-45 cells, when compared to that of mock cells. $\mathbf{C}$, in scratch migration assay, administration of $0.05,0.1$ and $0.2 \mathrm{mM} \mathrm{MJ}$ attenuated the migration capabilities of SGC-7901 and MKN-45 cells in a dose- and time-dependent manner, when compared to those of mock cells. D, transwell analysis indicated that administration of sub-cytotoxic MJ $(0.05,0.1$ and $0.2 \mathrm{mM})$ impaired the invasion capacities of SGC-7901 and MKN-45 cells in a dose- and time-dependent manner, than those of mock cells. $\mathbf{E}$, the tube formation of endothelial cells was dose- and time-dependently suppressed by the medium preconditioned by treatment of gastric cancer cells with sub-cytotoxic MJ $(0.05,0.1$ and $0.2 \mathrm{mM})$, than that of mock cells. The symbol $\left({ }^{*}\right)$ indicates a significant decrease from mock.

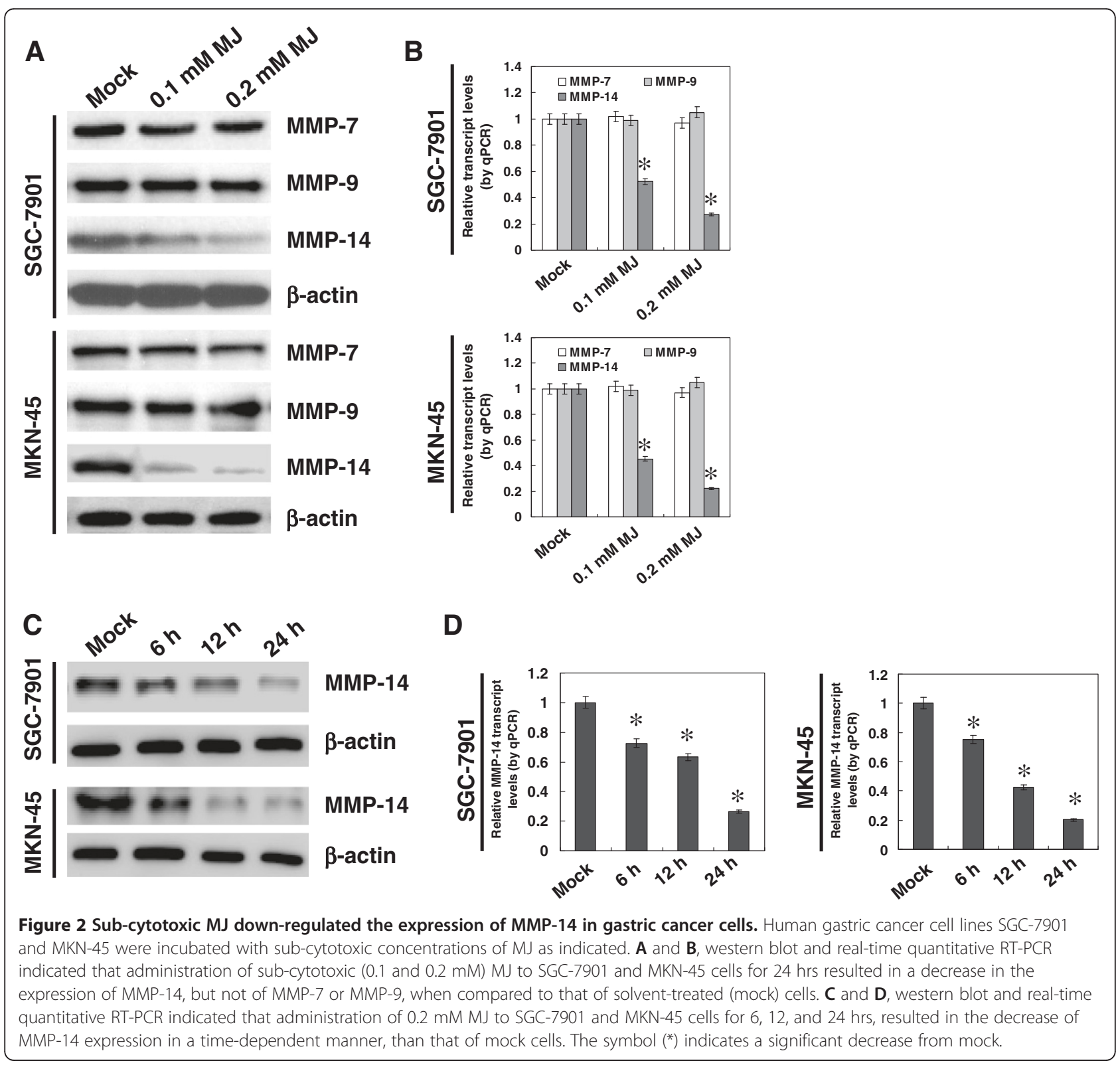


to remove detached cells, and incubated with the complete growth medium. Cell migration was photographed using 10 high-power fields, at 0 and $24 \mathrm{hrs}$ post-induction of injury. Remodeling was measured as diminishing distance across the induced injury, normalized to the $0 \mathrm{hr}$ control, and expressed as outgrowth $(\mu \mathrm{m})[16]$.

\section{Matrigel invasion assay}

The Boyden chamber technique (transwell analysis) was performed as previously described [16]. Cancer cells were treated with $\mathrm{MJ}$ or solvent. Homogeneous single cell suspensions $\left(1 \times 10^{5}\right.$ cells/well $)$ were added to the upper chambers, and allowed to invade for $24 \mathrm{hrs}$ at $37^{\circ} \mathrm{C}$ in a $\mathrm{CO}_{2}$ incubator. Migrated cells were stained with $0.1 \%$ crystal violet for $10 \mathrm{~min}$ at room temperature and examined by light microscopy. Quantification of migrated cells was performed according to published criteria [17].

\section{Tube formation assay}

Fifty microliters of growth factor-reduced matrigel were polymerized on 96-well plates. HUVECs were serum starved in RPMI1640 medium for $24 \mathrm{hrs}$, suspended in RPMI1640 medium preconditioned with MJ- or solventtreated cancer cells, added to the matrigel-coated wells at the density of $5 \times 10^{4}$ cells/well, and incubated at $37^{\circ} \mathrm{C}$ for $18 \mathrm{hrs}$. Quantification of anti-angiogenic activity was calculated by measuring the length of tube walls formed between discrete endothelial cells in each well relative to the solvent control [18].

\section{Over-expression or knockdown of MMP-14 and Sp1}

Human MMP-14 cDNA (1749 bp) expression construct was established as previously described [16]. Human Sp1 cDNA (2358 bp) was amplified from cancer tissue and subcloned into the Hind III and Xha I restrictive sites of pcDNA3.1/Zeo(+) (Invitrogen) (Additional file 1: Table $\mathrm{S} 1)$. To restore the MJ-induced down-regulation of MMP-14 or Sp1, cancer cells were transfected with the recombinant vector pcDNA3.1-MMP14 or pcDNA3.1Sp1 for $72 \mathrm{hrs}$ before administration of MJ or solvent. The 21-nucleotide small interfering RNA (siRNA) targeting the encoding region of MMP-14 was chemically synthesized (RiboBio Co. Ltd; Additional file 1: Table S1) and transfected with Genesilencer Transfection Reagent (Genlantis, San Diego, CA). The scramble siRNA (siScb) was applied as controls (Additional file 1: Table S1). To monitor the transfection efficiency, the cancer cells were co-transfected with pEGFP-N1 (Clontech, Mountair View, CA).

\section{Western blot}

Tissue or cellular protein was extracted with $1 \times$ cell lysis buffer (Promega, Madison, WI). Western blot was performed as previously described [16,19], with antibodies specific for matrix metalloproteinase 7 (MMP-7), matrix metalloproteinase 9 (MMP-9), MMP-14, vascular endothelial growth factor (VEGF), Sp1, and $\beta$-actin (Santa Cruz Biotechnology, Santa Cruz, CA). Enhanced chemiluminescence substrate kit (Amersham, Piscataway, NJ) was used for the detection of signals with autoradiography film (Amersham).

\section{Real-time quantitative RT-PCR}

Total RNA was isolated with RNeasy Mini Kit (Qiagen Inc., Valencia, CA). The reverse transcription reactions were conducted with Transcriptor First Strand cDNA Synthesis Kit (Roche, Indianapolis, IN). The PCR primers for MMP-7, MMP-9, MMP-14, VEGF, Sp1 and $\beta$-actin were designed by Premier Primer 5.0 software (Additional file 2: Table S2). Real-time quantitative RT-PCR with SYBR Green PCR Master Mix (Applied Biosystems, Foster City, CA) was performed as previously described [16,19], using ABI Prism 7700 Sequence Detector (Applied Biosystems). The fluorescent signals were collected during extension phase, $\mathrm{Ct}$ values of the samples were calculated, and the transcript levels were analyzed by $2^{-\Delta \Delta C t}$ method.

\section{Chromatin immunoprecipitation}

Chromatin immunoprecipitation (ChIP) assay was performed according to the manufacture's instructions of EZ-ChIP kit (Upstate Biotechnology, Temacula, CA) [19]. The PCR primers surrounding the MMP-14 transcription start site were previously described [20]. Real-time quantitative PCR (qPCR) with SYBR Green PCR Master Mix was performed using ABI Prism 7700 Sequence Detector. The amount of immunoprecipitated DNA was calculated in reference to a standard curve and normalized to input DNA.

\section{Statistical analysis}

Unless otherwise stated, all data were shown as mean \pm standard error of the mean (SEM). The SPSS 12.0 statistical software (SPSS Inc., Chicago, IL) was applied for statistical analysis. Pearson's coefficient correlation was applied for analyzing the relationship between Sp1 expression and MMP-14 transcript levels. Difference of cancer cells was determined by $t$ test or analysis of variance (ANOVA).

\section{Results}

Sub-cytotoxic MJ attenuated the migration, invasion and angiogenesis of gastric cancer cells

Since previous studies imply the anti-metastatic and anti-angiogenic properties of MJ [21,22], we hypothesized that MJ might influence the migration, invasion and angiogenesis of cultured gastric cancer cells. We first identified the sub-cytotoxic concentrations of $\mathrm{MJ}$ 

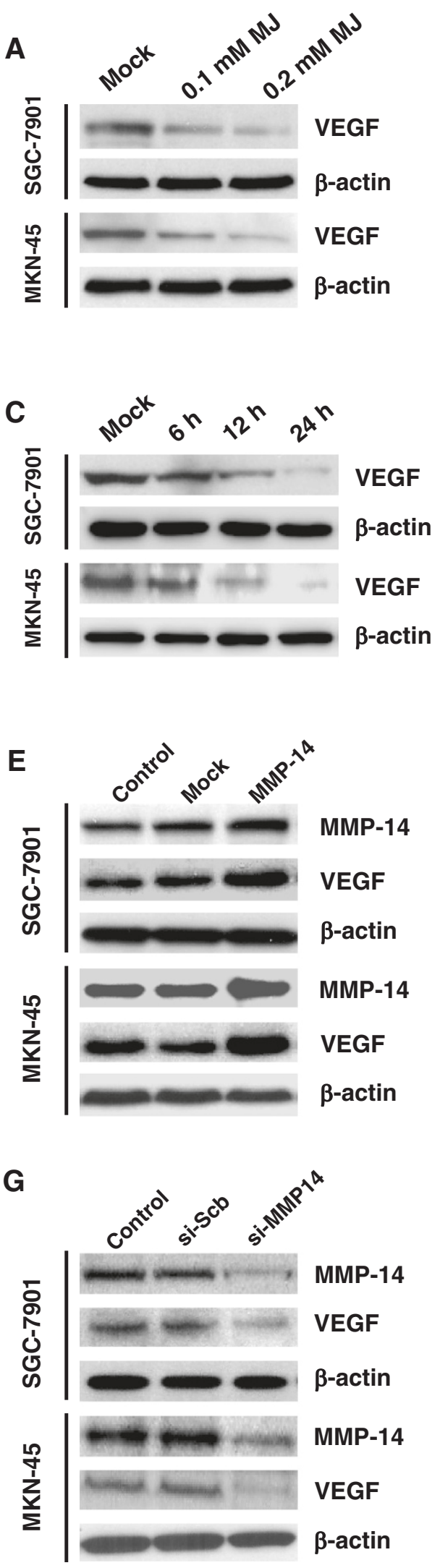

Figure 3 (See legend on next page.)
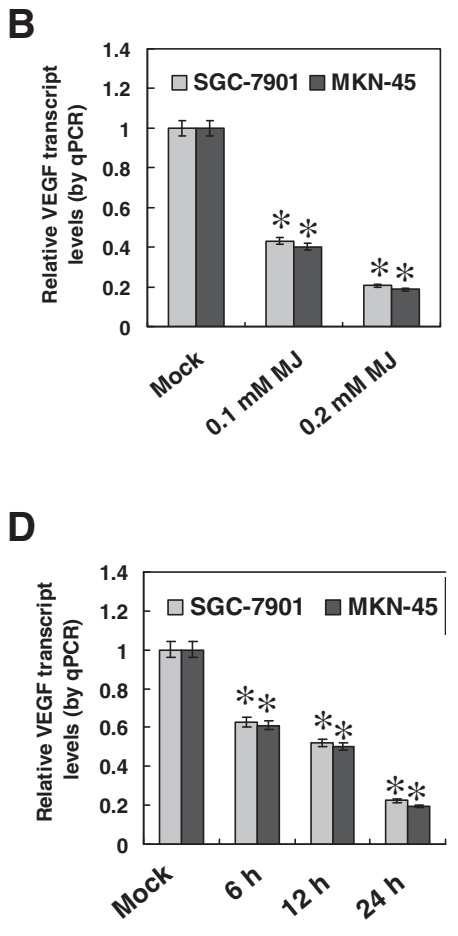

$\mathbf{F}$
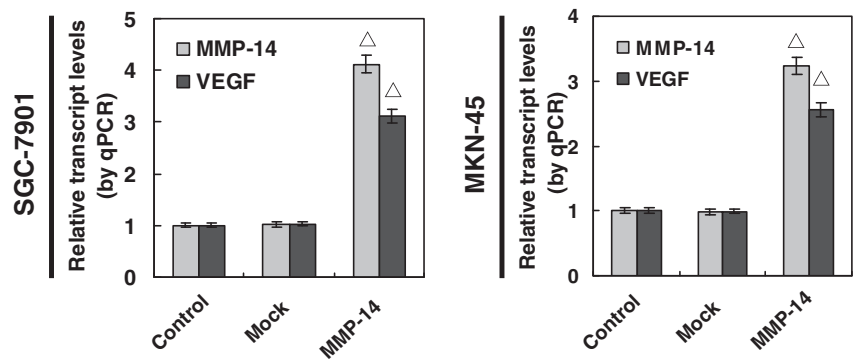

H
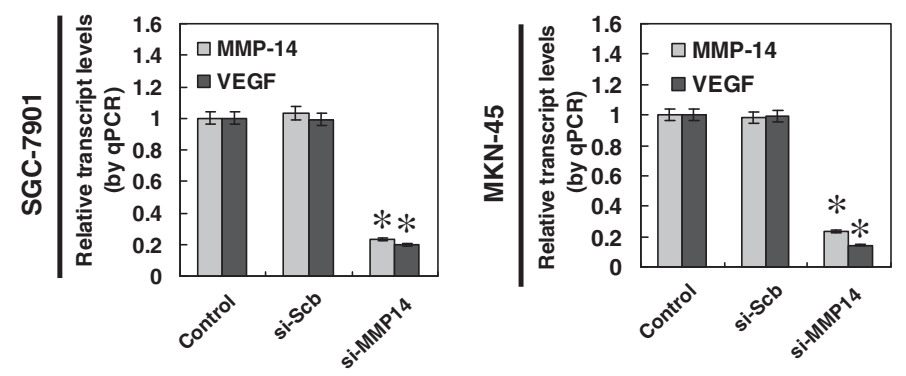
(See figure on previous page.)

Figure 3 Sub-cytotoxic MJ suppressed the expression of VEGF in gastric cancer cells. Human gastric cancer cell lines SGC-7901 and MKN45 were incubated with sub-cytotoxic concentrations of $\mathrm{MJ}$ as indicated. $\mathbf{A}$ and $\mathbf{B}$, western blot and real-time quantitative RT-PCR indicated that administration of sub-cytotoxic (0.1 and $0.2 \mathrm{mM}$ ) MJ to SGC-7901 and MKN-45 cells for 24 hrs resulted in a decrease in the expression of VEGF, when compared to that of solvent-treated (mock) cells. C and $\mathbf{D}$, western blot and real-time quantitative RT-PCR indicated that administration of $0.2 \mathrm{mM} \mathrm{MJ}$ to SGC-7901 and MKN-45 cells for 6, 12, and 24 hrs, resulted in the decrease of VEGF expression in a time-dependent manner, than that of mock cells. $\mathbf{E}$ and $\mathbf{F}, 72$ hrs post-transfection of MMP-14 expression vector into SGC-7901 and MKN-45 cells, western blot and real-time quantitative RT-PCR indicated the over-expressed MMP-14 and VEGF than that of empty vector-transfected (mock) cells. $\mathbf{G}$ and $\mathbf{H}, 24$ hrs posttransfection of si-MMP14 (100 nmol/L) into SGC-7901 and MKN-45 cells, western blot and real-time quantitative RT-PCR indicated the downregulated MMP-14 and VEGF than those transfected with scramble siRNA (si-Scb, $100 \mathrm{nmol} / \mathrm{L})$. The symbols $\left({ }^{*}\right.$ and $\Delta$ ) indicate a significant decrease and a significant increase from mock or si-Scb, respectively.

via a dose-response analysis in SGC-7901 and MKN-45 cells. As shown in Figure 1A, MJ suppressed the cell viabilities of gastric cancer cells with a range of concentrations ( 0.5 to $2.0 \mathrm{mM}$ ), while lower concentrations of MJ (0.05 to $0.2 \mathrm{mM}$ ) exerted no obvious cytotoxicity. The $\mathrm{IC}_{50}$ of MJ on SGC-7901 and MKN-45 cells were 1.72 and $1.24 \mathrm{mM}$, respectively. EdU incorporation assay was applied to further study the influence of subcytotoxic MJ on the proliferation of gastric cancer cells. As shown in Figure $1 \mathrm{~B}$ and Additional file 3: Figure S1, administration of sub-cytotoxic $(0.05,0.1$ and $0.2 \mathrm{mM})$ MJ did not attenuate the cell viabilities or proliferation. In scratch migration assay, sub-cytotoxic MJ attenuated the migration capabilities of SGC-7901 and MKN-45 cells in a dose- and time-dependent manner (Figure 1C). Transwell analysis showed that gastric cancer cells treated with sub-cytotoxic $(0.05,0.1$ and $0.2 \mathrm{mM}) \mathrm{MJ}$ presented a dose- and time-dependently impaired invasion capacity than solvent-treated (mock) cells (Figure 1D). The tube formation of endothelial cells was dose- and time-dependently suppressed by the medium preconditioned by treatment of gastric cancer cells with $0.05,0.1$ and $0.2 \mathrm{mM} \mathrm{MJ}$ (Figure 1E). However, the proliferation of endothelial HUVEC cells was not affected by subcytotoxic MJ (Additional file 4: Figure S2), ruling out the possibility that sub-cytotoxic MJ affected the angiogenesis through direct cytotoxicity on endothelial cells. These results indicated that sub-cytotoxic MJ attenuated the migration, invasion and angiogenesis of gastric cancer cells in vitro.

Sub-cytotoxic MJ down-regulated the expression of MMP14, but not of MMP-7 and MMP-9, in gastric cancer cells

Since previous studies reveal the critical roles of MMP-7, MMP-9 and MMP-14 in the invasion and metastasis of gastric cancer [23], we hypothesized that MJ might influence the expression of these genes. Western blot indicated that administration of sub-cytotoxic ( 0.1 and $0.2 \mathrm{mM}) \mathrm{MJ}$ resulted in a decrease in the expression of MMP-14, but not of MMP-7 or MMP-9, in cultured gastric cancer SGC-7901 and MKN-45 cells (Figure 2A). Real-time quantitative RT-PCR revealed the decreased transcript levels of MMP-14, but not of MMP-7 or MMP-9, in gastric cancer cells treated with sub-cytotoxic MJ (Figure 2B). In addition, sub-cytotoxic MJ-mediated inhibition on MMP-14 expression was in a time-dependent manner (Figure $2 \mathrm{C}$ and $\mathrm{D}$ ). These results indicated that sub-cytotoxic MJ suppressed the MMP-14 expression in gastric cancer cells.

\section{Sub-cytotoxic MJ suppressed the expression of VEGF in gastric cancer cells}

Since previous studies indicate that MMP-14 can regulate the VEGF expression in breast cancer cells [24], and combining the evidence that VEGF participates in the angiogenesis [25], we hypothesized that sub-cytotoxic MJ might also influence the expression of VEGF in gastric cancer cells. Western blot and real-time quantitative RT-PCR indicated that administration of sub-cytotoxic ( 0.1 and 0.2 $\mathrm{mM}) \mathrm{MJ}$ resulted in a significant decrease of VEGF expression in gastric cancer SGC-7901 and MKN-45 cells, which was consistent with MMP-14 reduction (Figure 3A and $\mathrm{B}$ ). In addition, sub-cytotoxic MJ-mediated inhibition on VEGF expression was in a time-dependent manner (Figure 3C and D). Furthermore, over-expression or knockdown of MMP-14 promoted or suppressed the VEGF expression in gastric cancer cells, respectively (Figure 3E, F, G and H), suggesting that as a direct downstream gene of MMP-14, the change of VEGF expression in sub-cytotoxic MJ-treated cancer cells may be due to the down-regulation of MMP-14.

\section{Over-expression of MMP-14 rescued sub-cytotoxic MJ- mediated suppression on VEGF expression, migration, invasion and angiogenesis of gastric cancer cells}

To further investigate the role of MMP-14 down-regulation in MJ-induced decrease in the migration, invasion and angiogenesis, MMP-14 expression construct was transfected into gastric cancer cells. The transfection efficiency was monitored by co-transfection with the enhanced green fluorescent protein (EGFP) reporter vector. Seventy-two hrs post-transfection, EGFP expressed within the cytoplasm of cancer cells, with the transfection efficiency around 60\% (Additional file 5: Figure S3). As shown in Figure 4A and B, transfection of SGC-7901 and MKN-45 cells with MMP-14 construct restored the sub-cytotoxic 
MJ-attenuated expression of MMP-14 and VEGF. Restoration of MMP-14 expression rescued the SGC-7901 and MKN-45 cells from their defects in migration, invasion, and angiogenesis induced by sub-cytotoxic (0.2 $\mathrm{mM}) \mathrm{MJ}$ (Figure 4C, D, and E). These results suggested that subcytotoxic MJ-induced suppression of migration, invasion and angiogenesis of gastric cancer cells, at least in part, was due to down-regulation of MMP-14 and its downstream gene VEGF.
Sub-cytotoxic MJ suppressed the expression and binding of Sp1 on MMP-14 promoter

Previous studies have revealed the critical role of transcription factor Sp1 in the regulation of MMP-14 expression in cancer cells [20]. To further explore the underlying mechanism for sub-cytotoxic MJ-induced MMP-14 down-regulation, cancerous and adjacent nonneoplastic tissues from twenty gastric cancer patients were collected for the analysis of Sp1, MMP-14, and

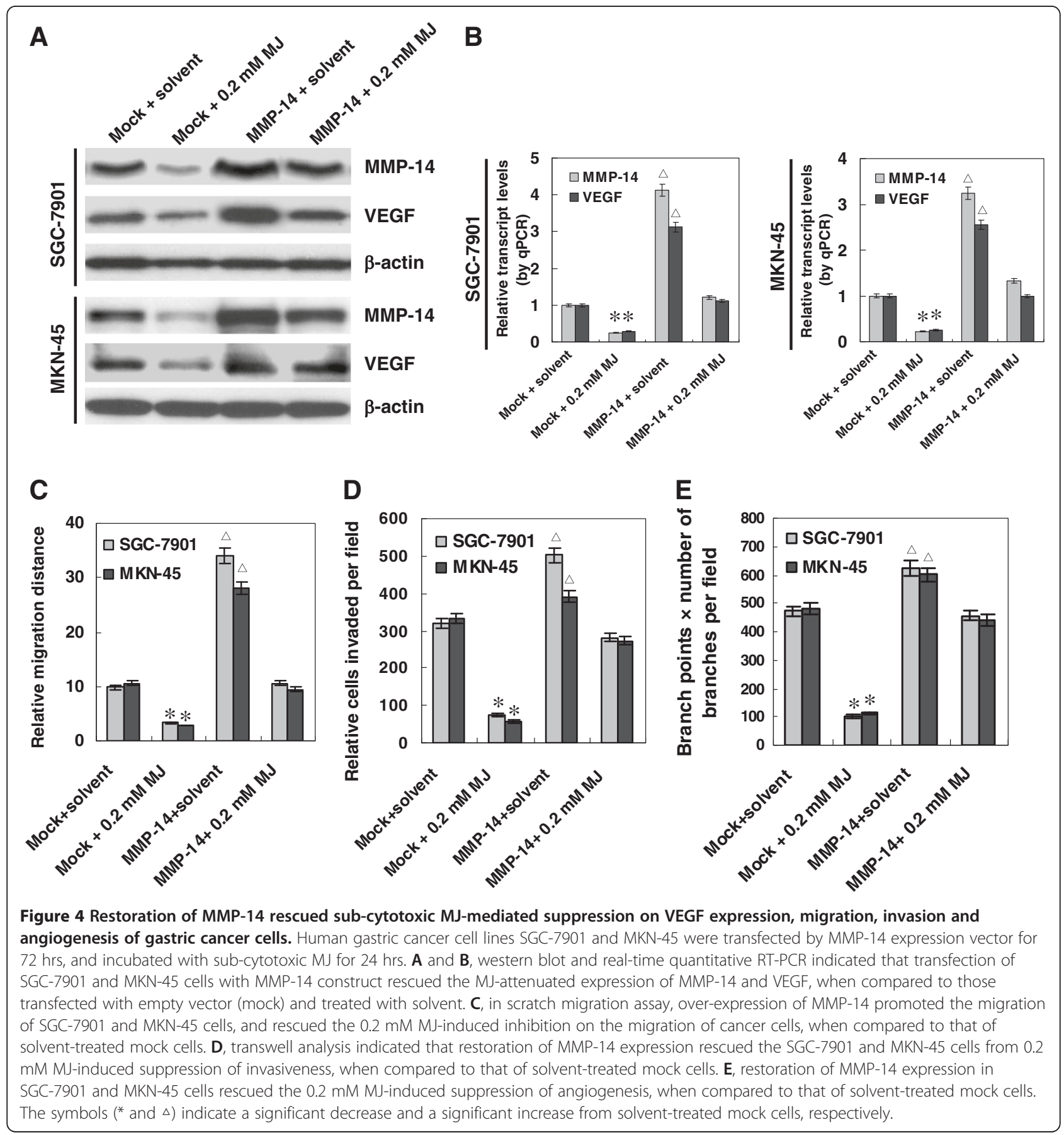




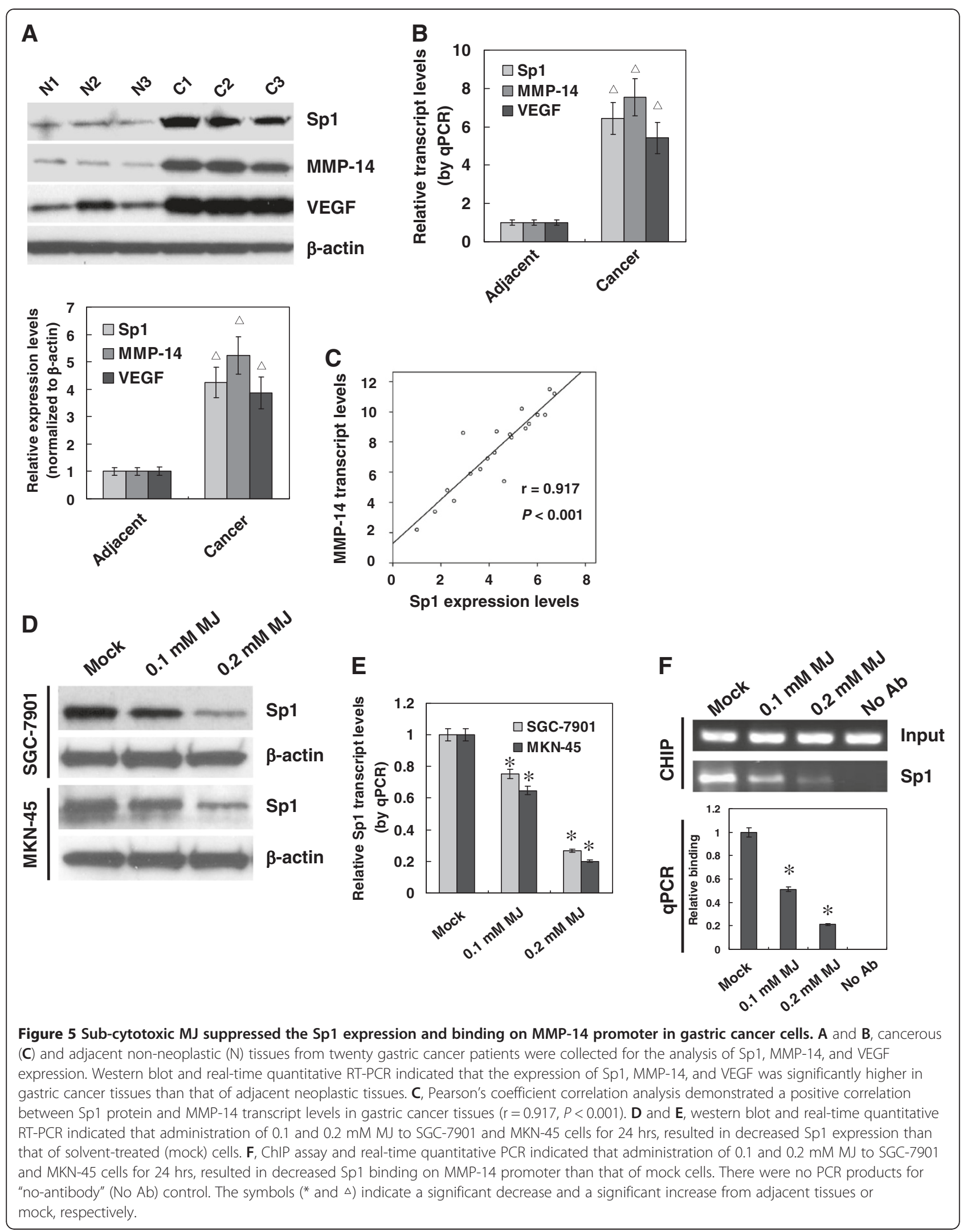


RT-PCR indicated that the expression of Sp1, MMP-14, and VEGF was significantly higher in gastric cancer tissues than that of adjacent non-neoplastic tissues (Figure 5A and B). Importantly, there was a positive correlation between Sp1 protein and MMP-14 transcript levels in gastric cancer tissues (Figure 5C). Administration of subcytotoxic (0.1 and $0.2 \mathrm{mM}$ ) MJ resulted in a decrease in the Sp1 expression in gastric cancer SGC-7901 and MKN45 cells (Figure 5D and E). ChIP assay further revealed the decreased binding of Sp1 on MMP-14 promoter in cancer cells treated with sub-cytotoxic MJ (Figure 5F). These findings indicated that sub-cytotoxic MJ attenuated the MMP-14 expression via decreasing the Sp1 expression and binding on MMP-14 promoter in gastric cancer cells.

\section{Restoration of Sp1 rescued sub-cytotoxic MJ-mediated suppression on MMP-14 expression, migration, invasion and angiogenesis of gastric cancer cells}

Since above evidence showed that $\mathrm{Sp} 1$ participated in the transcriptional regulation of MMP-14 in gastric cancer, we proposed that Sp1 might play an important role in subcytotoxic MJ-induced decrease in the migration, invasion and angiogenesis of gastric cancer cells. Human Sp1 expression construct was established and transfected into cancer cells. As shown in Figure 6A and B, transfection of SGC-7901 and MKN-45 cells with Sp1 construct rescued the sub-cytotoxic MJ-attenuated MMP-14 expression. Restoration of Sp1 into SGC-7901 and MKN-45 cell lines rescued the decrease in migration, invasion, and angiogenesis induced by sub-cytotoxic $(0.2 \mathrm{mM}) \mathrm{MJ}$ (Figure 6C, D, and E). These results suggested that subcytotoxic MJ-induced decrease in Sp1 expression contributed to down-regulation of MMP-14 and suppression of migration, invasion and angiogenesis of gastric cancer cells.

\section{Discussion}

In 2002, Fingrut et al. first reported the jasmonatesmediated suppression of cellular proliferation and induction of cell death in various human and mouse cancer cell lines, including breast cancer, prostate cancer, melanoma, lymphoblastic leukemia, and lymphoma [6]. In the past decade, several groups have demonstrated that members of jasmonate family and their synthetic derivatives exhibit anti-cancer activity on other kinds of tumor cells, including lung cancer [26], colon cancer [27], glioma [28], cervical cancer [29,30], neuroblastoma [12,13], and myeloid leukemia [31,32]. To date, several mechanisms have been proposed to explain the anti-cancer effects of jasmonates, including induction of severe ATP depletion via mitochondrial perturbation [33], induction of re-differentiation via mitogen-activated protein kinase activity [31], induction of a significant decrease in survivin levels via the $\beta$-catenin/T-cell factor pathway [27], and induction of apoptosis via pro-apoptotic proteins of the Bcl-2 family [34], opening the mitochondrial permeability transition pore complex [11] and activation of extrinsic apoptotic pathway [35]. However, the anti-cancer activity of sub-cytotoxic jasmonates and underlying mechanisms still warrant further investigation.

Recent evidence shows that MJ can inhibit melanoma cell migration and suppress the development of melanoma growth in mouse lungs [21], suggesting the potential anti-metastatic activities of MJ. In the current study, we demonstrated that in addition to the cytotoxic properties of MJ in cancer therapy, sub-cytotoxic MJ attenuated the migration and invasion of human gastric cancer SGC-7901 and MKN-45 cells. The SGC-7901 cell line was first established from the metastatic lymph node of a 56-year-old female patient suffering from gastric adenocarcinoma [36], while the MKN-45 cell line was derived from a metastatic liver tumor of a 62-year-old female with gastric cancer [37]. It is well known that the extracellular matrix (ECM) is a barrier to prevent tumor cells from invasion and metastasis [38]. Specific enzymes produced by cancer cells and activated by certain signals, such as matrix metalloproteinases (MMPs), have been reported to degrade ECM, and are associated with the progression of gastric cancer [23,39]. MMP-14, also named as membrane type-1 matrix metalloproteinase, functions as a pericellular collagenase and plays an important role in tumor invasion and metastasis by facilitating the cancer cells to remodel and penetrate ECM [40-42]. Clinical evidence has shown the linkage between high MMP-14 expression and cancer progression, such as lymph node metastases, invasion, poor clinical stage, larger tumor size, and increasing tumor stage [43]. In this study, we found that sub-cytotoxic MJ selectively down-regulated the expression of MMP-14, but not of MMP-7 and MMP-9, in gastric cancer cells. In addition, restoration of MMP-14 rescued the sub-cytotoxic MJinduced inhibition on the migration and invasion of cancer cells, suggesting the role of MMP-14 down-regulation in the anti-metastatic activities of sub-cytotoxic MJ.

Since MMP-14-mediated degradation of ECM occurs throughout the angiogenic process and contributes to vascular regression [41], we further demonstrated that sub-cytotoxic MJ attenuated the angiogenic capabilities of gastric cancer cells. In addition, sub-cytotoxic MJ did not induce the cell death of human umbilical vein endothelial cells, ruling out the influence of direct cytotoxicity on angiogenesis. In a previous study, MJ was noted to consistently impair the vascular growth in the Chorioallantoic model of angiogenesis [22], while the underlying mechanisms remain largely unknown. VEGF, a dimeric and heparin-binding glycoprotein that functions as a potent mitogen of vascular endothelial cells, is a major inducer of angiogenesis that can promote the growth and metastasis 
of tumors [25]. In this study, for the first time, we demonstrate that VEGF functions as a downstream gene of MMP-14 in gastric cancer cells. Since our findings indicated that sub-cytotoxic MJ abolished the VEGF expression in gastric cancer cells, combining the evidence that restoration of VEGF expression through MMP-14 overexpression rescued the decrease in tube formation of endothelial cells, we believe that the decreased expression of MMP-14 and downstream VEGF, at least in part, contributes to the anti-angiogenic function of subcytotoxic MJ in gastric cancer cells.

To elucidate the mechanisms underlying the downregulation of MMP-14 by sub-cytotoxic MJ, we further demonstrated that the MMP-14 transcript levels were abolished in MJ-treated gastric cancer cells. Because of the lack of typical TATA box and the presence of a GCrich sequence immediately upstream of the transcriptional start sites within the promoter, the transcriptional

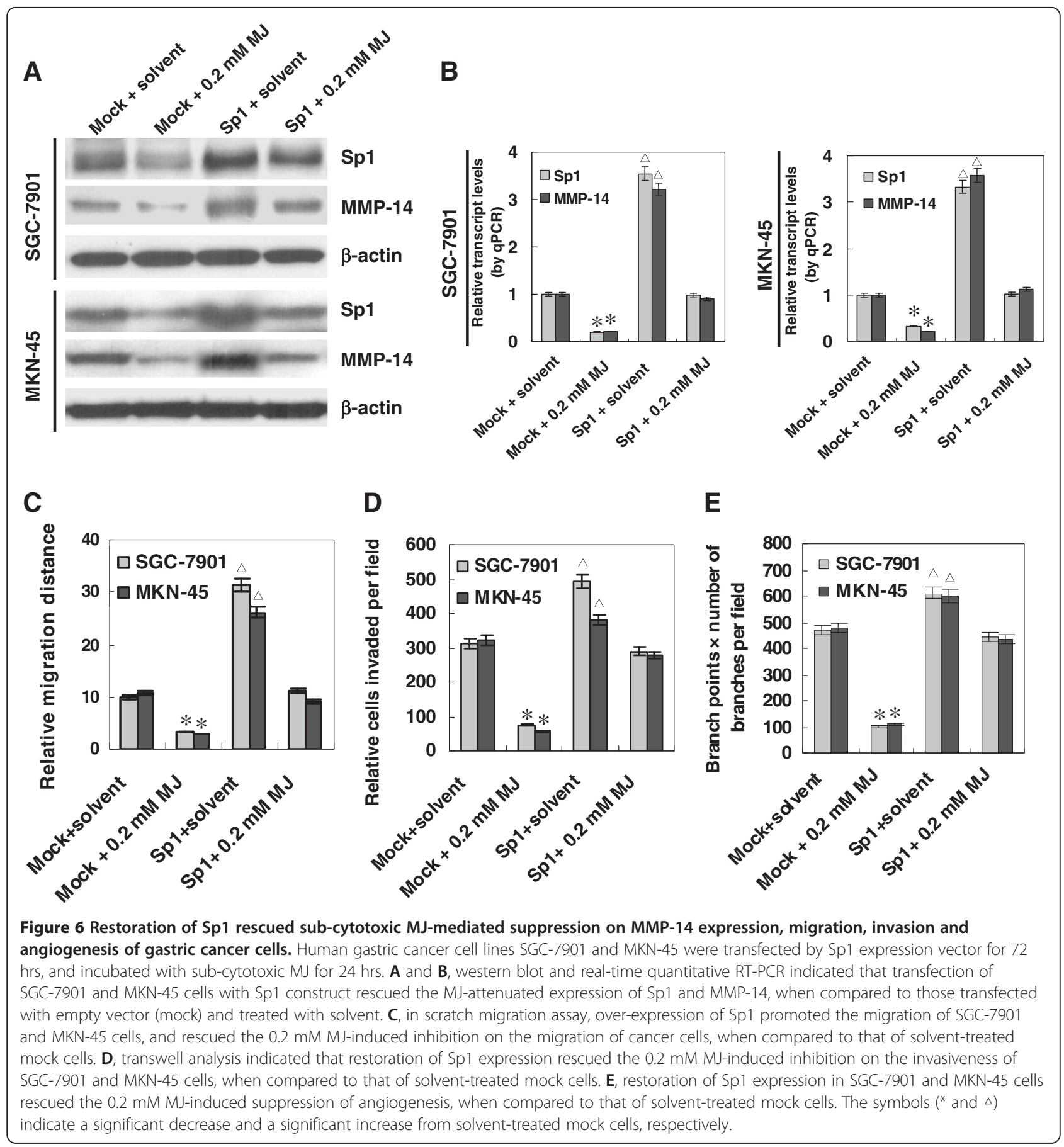


control of MMP-14 is unique compared to other MMP family members [44]. The GC-rich region within human MMP-14 promoter serves as the putative binding site for transcription factor $\mathrm{Sp} 1$ in fibrosarcoma and prostate cancer cells $[20,44]$. In addition, constitutive Sp1 binding to the MMP-14 promoter was also noted in rat glomerular mesangial cells [45]. In this study, we demonstrated the over-expressed $\mathrm{Sp} 1$ and its positive correlation with MMP-14 transcription in gastric cancer tissues. Then, we sought to determine whether $\mathrm{Sp} 1$ played a role in regulating MMP-14 in gastric cancer cells. Electrophoretic mobility shift assay is a traditional method to investigate the transcription factor-DNA interaction via studying the binding of protein to known DNA oligonucleotide probes [46]. However, this method is an in vitro assay and relatively difficult to be quantified [46]. In recent years, ChIP assay is an alternative method to monitor transcriptional regulation through transcription factor-DNA binding interaction in living cells, which is quantitative when coupled with qPCR analysis [46]. Here, we showed that Sp1 bound to the MMP-14 promoter in gastric cancer cells via ChIP assay. Additionally, administration of subcytotoxic MJ attenuated the Sp1 expression and binding to MMP-14 promoter, implying the important role of Sp1 in sub-cytotoxic MJ-induced down-regulation of MMP-14 in gastric cancer cells.

\section{Conclusions}

In summary, we demonstrate, for the first time, that subcytotoxic MJ attenuates the MMP-14 expression via decreasing the Sp1 expression and binding on MMP-14 promoter, thus inhibiting the migration, invasion and angiogenesis of gastric cancer cells. These findings support the notion that in addition to its cytotoxic activity, subcytotoxic MJ exerts anti-metastatic and anti-angiogenic functions as well. These results lay the groundwork for further investigation into the mechanisms of MJ-mediated anti-cancer functions, which is of potential values as a novel therapeutic approach for gastric cancer.

\section{Additional files}

Additional file 1: Table S1. Oligonucleotide sets used for constructs and small interfering RNAs.

Additional file 2: Table S2. Primer sets used for qRT-PCR.

Additional file 3: Figure S1. Time-course effects of

sub-cytotoxic MJ on the viability of gastric cancer cells. Human gastric cancer SGC-7901 and MKN-45 cells were incubated with sub-cytotoxic (0.05, 0.1 and $0.2 \mathrm{mM}) \mathrm{MJ}$ for 6,12 and 24 hrs. MTT colorimetric assay indicated that sub-cytotoxic MJ did not affect the viabilities of gastric cancer cells, when compared to those treated by solvent (mock).

Additional file 4: Figure S2. Sub-cytotoxic MJ did not affect the proliferation of human endothelial cells. Human endothelial HUVEC cells were incubated with sub-cytotoxic $(0.05,0.1$ and $0.2 \mathrm{mM}) \mathrm{MJ}$ for $24 \mathrm{hrs}$. EdU incorporation assay indicated that sub-cytotoxic MJ did not affect the proliferation of HUVEC cells, when compared to those treated by solvent (mock).

Additional file 5: Figure S3. Transfection efficiency assay. Confluent monolayers of gastric cancer SGC-7901 and MKN-45 cells were transfected with the enhanced green fluorescent protein (EGFP) reporter vector pEGFP-N1. Seventy-two hrs post-transfection, EGFP expressed within the cytoplasm of cancer cells, with the transfection efficiency around $60 \%$.

\section{Competing interests}

The authors declare that they have no competing interests.

\section{Authors' contributions}

QT and LZ conceived and designed study. LZ, DL, and XX performed the experiments. DL provided coordination. MQ, JP, KH, QT, and LZ analyzed the data. QT and LZ provided grant support and wrote the paper. All authors have read and approved the final manuscript.

\section{Acknowledgement}

This work was supported by the National Natural Science Foundation of China (No. 30600278, No. 30772359, No. 81071997, No. 81072073, No. 81272779), Program for New Century Excellent Talents in University (NCET06-0641), Scientific Research Foundation for the Returned Overseas Chinese Scholars (2008-889), and Fundamental Research Funds for the Central Universities (2012QN224).

\section{Author details}

'Department of Pathology, Union Hospital of Tongji Medical College, Huazhong University of Science and Technology, Wuhan, Hubei Province 430022, People's Republic of China. ${ }^{2}$ Clinical Center of Human Genomic Research, Union Hospital of Tongji Medical College, Huazhong University of Science and Technology, Wuhan, Hubei Province 430022, People's Republic of China. ${ }^{3}$ Department of Surgery, Union Hospital of Tongji Medical College, Huazhong University of Science and Technology, Wuhan, Hubei Province 430022, People's Republic of China. ${ }^{4}$ Department of Cardiology, Union Hospital of Tongji Medical College, Huazhong University of Science and Technology, Wuhan, Hubei Province 430022, People's Republic of China.

Received: 17 September 2012 Accepted: 30 January 2013

Published: 10 February 2013

\section{References}

1. Jemal A, Bray F, Center MM, Ferlay J, Ward E, Forman D: Global cancer statistics. CA Cancer J Clin 2011, 61:69-90.

2. Terry MB, Gaudet MM, Gammon MD: The epidemiology of gastric cancer. Semin Radiat Oncol 2002, 12:111-127.

3. GASTRIC (Global Advanced/Adjuvant Stomach Tumor Research International Collaboration) Group PX, Oba K, Burzykowski T, Michiels S, Ohashi Y, Pignon JP, Rougier P, Sakamoto J, Sargent D, Sasako M, Van Cutsem E, Buyse M: Benefit of adjuvant chemotherapy for resectable gastric cancer: a meta-analysis. JAMA 2010, 303:1729-1737.

4. Cragg GM, Newman DJ: Plants as a source of anti-cancer and anti-HIV agents. Ann Appl Biol 2003, 143:127-133.

5. Cragg GM, Newman DJ: Plants as a source of anti-cancer agents. J Ethnopharmacol 2005, 100:72-79.

6. Fingrut $\mathrm{O}$, Flescher E: Plant stress hormones suppress the proliferation and induce apoptosis in human cancer cells. Leukemia 2002, 16:608-616

7. Ordan O, Rotem R, Jaspers I, Flescher E: Stress-responsive JNK mitogenactivated protein kinase mediates aspirin-induced suppression of B16 melanoma cellular proliferation. Br J Pharmacol 2003, 138:1156-1162.

8. Sembdner $G$, Parthier B: The biochemistry and the physiological and molecular actions of jasmonates. Annu Rev Plant Physiol Plant Mol Biol 1993, 44:569-589.

9. Cohen S, Flescher E: Methyl jasmonate: A plant stress hormone as an anti-cancer drug. Phytochemistry 2009, 70:1600-1609.

10. Flescher E: Jasmonates in cancer therapy. Cancer Lett 2007, 245:1-10.

11. Rotem R, Heyfets A, Fingrut O, Blickstein D, Shaklai M, Flescher E: Jasmonates: novel anticancer agents acting directly and selectively on human cancer cell mitochondria. Cancer Res 2005, 65:1984-1993. 
12. Tong Q, Jiang G, Zheng L, Tang S, Cai J, Liu Y, Zeng F, Dong J: Natural jasmonates of different structures suppress the growth of human neuroblastoma cell line SH-SY5Y and its mechanisms. Acta Pharmacol Sin 2008, 29:861-869.

13. Tong Q, Jiang G, Zheng L, Tang S, Cai J, Liu Y, Zeng F, Dong J: Methyl jasmonate downregulates expression of proliferating cell nuclear antigen and induces apoptosis in human neuroblastoma cell lines. Anti-Cancer Drugs 2008, 19:573-581.

14. Jiang G, Zhao J, Xiao X, Tao D, Gu C, Tong Q, Luo B, Wang L, Zeng F: AN $\mathrm{N}$-terminal Smac peptide sensitizes human prostate carcinoma cells to methyl jasmonate-induced apoptosis. Cancer Lett 2011, 302:37-46.

15. Zheng L, Jiang G, Mei H, Pu J, Dong J, Hou X, Tong Q: Small RNA interference-mediated gene silencing of heparanase abolishes the invasion, metastasis and angiogenesis of gastric cancer cells. BMC Cancer 2010, 10:33.

16. Zhang H, Qi M, Li S, Qi T, Mei H, Huang K, Zheng L, Tong Q: microRNA-9 targets matrix metalloproteinase 14 to inhibit invasion, metastasis, and angiogenesis of neuroblastoma cells. Mol Cancer Ther 2012, 11:1454-1466.

17. Valster A, Tran NL, Nakada M, Berens ME, Chan AY, Symons M: Cell migration and invasion assays. Methods 2005, 37:208-215.

18. Nicosia RF, Ottinetti A: Growth of microvessels in serum-free matrix culture of rat aorta. A quantitative assay of angiogenesis in vitro. Lab Invest 1990, 63:115-122.

19. Jiang G, Zheng L, Pu J, Mei H, Zhao J, Huang K, Zeng F, Tong Q: Small RNAs targeting transcription start site induce heparanase silencing through interference with transcription initiation in human cancer cells. PLoS One 2012, 7:e31379.

20. Sroka IC, Nagle RB, Bowden GT: Membrane-type 1 matrix metalloproteinase is regulated by sp1 through the differential activation of AKT, JNK, and ERK pathways in human prostate tumor cells. Neoplasia 2007, 9:406-417.

21. Reischer D, Heyfets A, Shimony S, Nordenberg J, Kashman Y, Flescher E: Effects of natural and novel synthetic jasmonates in experimental metastatic melanoma. Br J Pharmacol 2007, 150:738-749.

22. Pereira Lopes J, Barbosa M, Stella C, Santos W, Pereira E, Nogueira-Neto J, Augusto $E$, Silva L, Smaili S, Gomes L: In vivo anti-angiogenic effects further support the promise of the antineoplasic activity of methyl jasmonate. Braz J Biol 2010, 70:443-449.

23. Zhang M, Zhu GY, Gao HY, Zhao SP, Xue Y: Expression of tissue levels of matrix metalloproteinases and tissue inhibitors of metalloproteinases in gastric adenocarcinoma. J Surg Oncol 2011, 103:243-247.

24. Sounni NE, Devy L, Hajitou A, Frankenne F, Munaut C, Gilles C, Deroanne C, Thompson EW, Foidart JM, Noel A: MT1-MMP expression promotes tumor growth and angiogenesis through an up-regulation of vascular endothelial growth factor expression. FASEB J 2002, 16:555-564.

25. Hoeben A, Landuyt B, Highley MS, Wildiers H, Van Oosterom AT, De Bruijn EA: Vascular endothelial growth factor and angiogenesis. Pharmacol Rev 2004, 56:549-580.

26. Yeruva L, Pierre KJ, Carper SW, Elegbede JA, Toy BJ, Wang RC: Jasmonates induce apoptosis and cell cycle arrest in non-small cell lung cancer lines. Exp Lung Res 2006, 32:499-516.

27. Raviv Z, Zilberberg A, Cohen S, Reischer-Pelech D, Horrix C, Berger MR, Rosin-Arbesfeld R, Flescher E: Methyl jasmonate down-regulates survivin expression and sensitizes colon carcinoma cells towards TRAIL-induced cytotoxicity. Br J Pharmacol 2011, 164:1433-1444.

28. Oh SYKJ, Park MJ, Kim SM, Yoon CS, Joo YM, Park JS, Han SI, Park HG, Kang HS: Induction of heat shock protein 72 in C6 glioma cells by methyl jasmonate through ROS-dependent heat shock factor 1 activation. Int J Mol Med 2005, 16:833-839.

29. Milrot E, Jackman A, Kniazhanski T, Gonen P, Flescher E, Sherman L: Methy jasmonate reduces the survival of cervical cancer cells and downregulates HPV E6 and E7, and survivin. Cancer Lett 2012, 319:31-38.

30. Kniazhanski T, Jackman A, Heyfets A, Gonen P, Flescher E, Sherman L: Methyl jasmonate induces cell death with mixed characteristics of apoptosis and necrosis in cervical cancer cells. Cancer Lett 2008, 271:34-46.

31. Ishii $Y$, Kiyota H, Sakai S, Honma Y: Induction of differentiation of human myeloid leukemia cells by jasmonates, plant hormones. Leukemia 2004, 18:1413-1419.

32. Tsumura $H$, Akimoto $M$, Kiyota $H$, Ishii $Y$, Ishikura $H$, Honma $Y$ : Gene expression profiles in differentiating leukemia cells induced by methyl jasmonate are similar to those of cytokinins and methyl jasmonate analogs induce the differentiation of human leukemia cells in primary culture. Leukemia 2008, 23:753-760

33. Fingrut $\mathrm{O}$, Reischer $\mathrm{D}$, Rotem R, Goldin N, Altboum I, Zan-Bar I, Flescher E: Jasmonates induce nonapoptotic death in high-resistance mutant p53-expressing B-lymphoma cells. Br J Pharmacol 2005, 146:800-808.

34. Kim JHLS, Oh SY, Han SI, Park HG, Yoo MA, Kang HS: Methyl jasmonate induces apoptosis through induction of $\mathrm{Bax} / \mathrm{Bcl}-\mathrm{XS}$ and activation of caspase-3 via ROS production in A549 cells. Oncol Rep 2004, 12:1233.

35. Yeruva L, Elegbede JA, Carper SW: Methyl jasmonate decreases membrane fluidity and induces apoptosis through tumor necrosis factor receptor 1 in breast cancer cells. Anti-Cancer Drugs 2008, 19:766-776.

36. Lin CH, Fu ZM, Liu YL, Yang JL, Xu JF, Chen QS, Chen HM: Investigation of SGC-7901 cell line established from human gastric carcinoma cells. Chin Med J 1984, 97:831-834.

37. Motoyama T, Hojo H, Watanabe $\mathrm{H}$ : Comparison of seven cell lines derived from human gastric carcinomas. Acta Pathol Jpn 1986, 36:65-83.

38. Liotta LA, Stetler-Stevenson WG: Tumor invasion and metastasis: an imbalance of positive and negative regulation. Cancer Res 1991, 51:5054s-5059s

39. Kaneko T, Konno H, Baba M, Tanaka T, Nakamura S: Urokinase-type plasminogen activator expression correlates with tumor angiogenesis and poor outcome in gastric cancer. Cancer Sci 2003, 94:43-49.

40. Chun T-H, Sabeh F, Ota I, Murphy H, McDonagh KT, Holmbeck K, BirkedalHansen H, Allen ED, Weiss SJ: MT1-MMP-dependent neovessel formation within the confines of the three-dimensional extracellular matrix. J Cell Biol 2004, 167:757-767.

41. Aplin AC, Zhu WH, Fogel E, Nicosia RF: Vascular regression and survival are differentially regulated by MT1-MMP and TIMPs in the aortic ring model of angiogenesis. Am J Physiol Cell Physiol 2009, 297:C471-C480.

42. Sabeh F, Ota I, Holmbeck K, Birkedal-Hansen H, Soloway P, Balbin M, LopezOtin C, Shapiro S, Inada M, Krane S, Allen E, Chung D, Weiss SJ: Tumor cell traffic through the extracellular matrix is controlled by the membraneanchored collagenase MT1-MMP. J Cell Biol 2004, 167:769-781.

43. Jiang WGDG, Martin TA, Parr C, Watkins G, Mason MD, Mansel RE: Expression of membrane type-1 matrix metalloproteinase, MT1-MMP in human breast cancer and its impact on invasiveness of breast cancer cells. Int J Mol Med 2006, 17:583-590.

44. Lohi J, Lehti K, Valtanen H, Parks WC, Keski-Oja J: Structural analysis and promoter characterization of the human membrane-type matrix metalloproteinase-1 (MT1-MMP) gene. Gene 2000, 242:75-86.

45. Alfonso-Jaume MA, Mahimkar R, Lovett DH: Co-operative interactions between NFAT (nuclear factor of activated T cells) $\mathrm{c} 1$ and the zinc finger transcription factors Sp1/Sp3 and Egr-1 regulate MT1-MMP (membrane type 1 matrix metalloproteinase) transcription by glomerular mesangial cells. Biochem J 2004, 380:735-747.

46. Dey B, Thukral S, Krishnan S, Chakrobarty M, Gupta S, Manghani C, Rani V: DNA-protein interactions: methods for detection and analysis. Mol Cell Biochem 2012, 365:279-299.

\section{doi:10.1186/1471-2407-13-74}

Cite this article as: Zheng et al:: Methyl jasmonate abolishes the migration, invasion and angiogenesis of gastric cancer cells through down-regulation of matrix metalloproteinase 14. BMC Cancer 2013 13:74.

\section{Submit your next manuscript to BioMed Central and take full advantage of:}

- Convenient online submission

- Thorough peer review

- No space constraints or color figure charges

- Immediate publication on acceptance

- Inclusion in PubMed, CAS, Scopus and Google Scholar

- Research which is freely available for redistribution 